\title{
Políticas públicas e estratégias de reprodução social: o PAA para mulheres no Nordeste e no Norte do Brasil
}

\section{Public policies and social reproduction strategies - PAA for women in the Northeast and North of Brazil}

Dalva Maria da Mota - Doutora em Sociologia, pela Universidade Federal de Pernambuco/ Sam Houston State University. Pesquisadora da Embrapa Amazônia Oriental, Belém (PA). Bolsista de produtividade do CNPq. E-mail: dalva.mota@embrapa.br

Heribert Schmitz - Doutor em Sociologia Rural, pela Universidade Humboldt de Berlim (2002), na Alemanha. Professor de Sociologia da Universidade Federal do Pará (UFPA). Bolsista de produtividade do CNPq.E-mail: heri@zedat.fu-berlin.de

Jamille Ferreira Guimarães - Mestre em Agriculturas Familiares e Desenvolvimento Sustentável, pela Universidade Federal do Pará (UFPA). E-mail: jamille.guimaraes@ funcate.org.br

\section{Resumo}

$\mathrm{O}$ artigo trata do Programa de Aquisição de Alimentos (PAA) para mulheres extrativistas e agricultoras. Investiga-se como se configuram as estratégias de reprodução social de mulheres extrativistas e agricultoras no âmbito do PAA em localidades rurais do Nordeste e do Norte do Brasil, com base em dois estudos de caso: com extrativistas de mangaba na localidade Pontal, no município de Indiaroba (Sergipe), e com agricultoras no Trevo de Belterra, município de Belterra (Pará). Como principais procedimentos, foram entrevistadas todas as mulheres envolvidas com o PAA e registradas observações. A conclusão geral reforça os achados de outros analistas que descrevem o PAA como uma política que reúne objetivos econômicos e sociais: dinamizou processos produtivos, incentivou a organização das mulheres e contribuiu para um maior bemestar (dieta e bens móveis). Não obstante, esse programa deixou de ser prioritário desde 2016 e houve uma significativa redução dos recursos.

\section{Palavra-chave}

Catadoras de Mangaba. Agricultoras. Pontal. Trevo de Belterra.

\begin{abstract}
This article examines the Food Acquisition Program (Programa de Aquisição de Alimentos $P A A)$ geared toward women farmers and collectors. The central question guiding this work was: how are social reproduction strategies configured in the realm of PAA in rural locations in the Northeast and North of Brazil? To respond to this query, we conducted two case studies: one with mangaba collectors in Pontal, Indiaroba municipality (Sergipe); and another with female farmers in Trevo de Belterra, Belterra municipality (Pará). Interviews with all the women involved in PAA and observations were the main methods employed. As a general conclusion we corroborate findings of other analysists who describe PAA as a policy that unites economic and social objectives: it dynamized productive processes, incentivized womenss organization and led to greater well-being (diet and movable goods). Yet, since 2016, this program has not been given priority, and there has been a significant reduction in resources.
\end{abstract}

\section{Keywords}

Mangaba Collectors. Female Farmers. Pontal. Trevo de Belterra. 


\section{INTRODUÇÃO}

Neste artigo, tratamos da influência de uma política pública - o Programa de Aquisição de Alimentos $(\mathrm{PAA})^{1}$ - nas condições de reprodução social de mulheres extrativistas e agricultoras em comunidades rurais do Nordeste e do Norte do Brasil. Partimos do pressuposto do reconhecimento da coexistência de iniciativas de políticas públicas para as mulheres que vivem no mundo rural no Brasil. Nesse âmbito, têm papel de destaque os movimentos de mulheres rurais que atuam fortemente "[...] tanto na correção de rumos das políticas e na garantia de efetivação do acesso das mulheres aos direitos conquistados, como também no impulsionamento de mudanças culturais e de autopercepção do lugar das trabalhadoras das áreas rurais como atores sociais e políticos" (HEREDIA; CINTRÃO, 2006, p. 21). Não obstante tal reconhecimento, críticas persistem quanto ao aporte das políticas públicas para o aumento da satisfação e do bemestar das mulheres rurais (PAULILO, 2012).

Neste artigo, tratamos de mulheres extrativistas do fruto da mangabeira (Hancornia speciosa Gomes) autodesignadas "catadoras de mangaba", no povoado Pontal, município de Indiaroba (estado de Sergipe), e de agricultoras, produtoras de hortaliças no Trevo de Belterra, município de Belterra (estado do Pará). Nos dois casos, as mulheres acumulam experiência com o PAA, na modalidade Compra com Doação Simultânea ${ }^{2}$ (CDS). As catadoras de mangaba participaram do PAA de 2007 a 2011; a participação das agricultoras teve início em 2009 e foi encerrada em 2017 (SANTOS; SILVA; QUARESMA, 2018).

Os distintos momentos de participação no PAA condicionaram-nos metodologicamente a trabalhar com duas dimensões temporais: o passado recente, no caso das catadoras de mangaba, para analisar as influências do PAA no dia a dia e após o seu encerramento, e o presente, para compreender o programa no decorrer da sua operacionalização, no caso das agricultoras.

Para além dos diferentes tempos de participação no PAA, as mulheres também se distinguem quanto ao acesso aos recursos naturais dos quais dependem para sobreviver. Essa condição é agravada nos dois grupos, que, além de não

O PAA foi criado pelo artigo 19 da Lei n 10.696, de 2 de julho de 2003 (BRASIL, 2003), com as seguintes finalidades básicas: promover o acesso à alimentação a populações em situação de vulnerabilidade social e incentivar a agricultura familiar.

2 O Ministério do Desenvolvimento Social e Combate à Fome (MDS) repassava os recursos que eram executados pela Companhia Nacional de Abastecimento (Conab) e pelos estados e municípios. Nessa modalidade, os alimentos produzidos por agricultores familiares eram comprados e repassados para entidades integrantes da rede socioassistencial. O limite recebido por agricultor familiar, na época da pesquisa, era $\mathrm{R} \$ 4.500,00 /$ ano. 
terem acesso regular a serviços de assistência técnica, enfrentam pressões por causa da expansão dos monocultivos da agricultura empresarial nos arredores de onde vivem, como ocorre com a soja, em Belterra (PA), e com o eucalipto, em Indiaroba (SE). Os efeitos mais visíveis dessa expansão têm sido a pressão pela venda das terras no caso das agricultoras e, no segundo, a devastação de áreas nativas de mangabeiras nas quais as catadoras praticavam o extrativismo. As ameaças de expropriação nos dois casos potencializam a importância de ter acesso a políticas que reforcem a reprodução social compreendida como um processo que "[...] inclui todos os mecanismos institucionais, bem como atividades e normas ditadas pelo costume (costumarias), que servem para manter, suprir e transmitir o capital social de geração a geração" (FORTES, 2011, p. 6). Objetivamente, as estratégias de reprodução social constituem possibilidades de escolha para garantir a manutenção cotidiana e geracional do grupo (GARCÍA; OLIVEIRA, 2006), portanto, em curto e em longo prazos.

Considerando tal problemática, o objetivo do artigo é analisar como se configuram as estratégias de reprodução social de mulheres extrativistas e agricultoras no âmbito do PAA em localidades rurais do Nordeste e do Norte do Brasil.

Como analisado na literatura, o PAA é uma ação original e pioneira do Estado brasileiro para grupos de base familiar. O programa tem repercussão virtuosa por incentivar os arranjos institucionais (ZIMMERMANN, 2007) e o desenvolvimento local (GRISA et al., 2009; VALERIANO, 2012), com impactos positivos na vida dos agricultores (CHMIELEWSKA; SOUZA; LOURETE, 2010; DORETTO; MICHELLON, 2007) e, de modo mais específico, na das mulheres agricultoras (SILIPRANDI; CINTRÃO, 2011) e extrativistas (MOTA et al., 2014).

\section{A PESQUISA}

A pergunta que nos orientou no estudo foi: como se configuram as estratégias de reprodução social de mulheres extrativistas e agricultoras no âmbito do PAA em localidades rurais do Nordeste e do Norte do Brasil? Para responder a essa pergunta, duas experiências foram consideradas: a participação atual das agricultoras no PAA e os reflexos do PAA no cotidiano das catadoras de mangaba três anos após o encerramento de sua participação no programa ${ }^{3}$.

\footnotetext{
Pesquisa realizada com recursos da Empresa Brasileira de Pesquisa Agropecuária (Embrapa), da Universidade Federal do Pará (UFPA), do Conselho Nacional de Desenvolvimento Científico e Tecnológico (CNPq) e do Ministério de Desenvolvimento Social e Combate à Fome (MDS). Chamada 24/2013.
} 
Para a realização da pesquisa, articulamos as abordagens quantitativa e qualitativa. Realizamos dois estudos de caso, considerando que esse método possibilita adquirir conhecimento adequado dos fenômenos a partir da exploração intensa de um único ou de alguns casos (BECKER, 1997). O universo constituiu-se de $100 \%$ das mulheres que participaram do PAA e pertenciam a dois grupos: as catadoras de mangaba da localidade Pontal e as agricultoras do Trevo de Belterra, comunidades rurais localizadas nos municípios de Indiaroba (SE) e Belterra (PA), respectivamente (Mapa 1). Segundo o Instituto Brasileiro de Geografia e Estatística (IBGE, 2020), esses municípios caracterizam-se pela importância do extrativismo de madeira e dos cultivos de mandioca e de soja para o caso de Belterra, e pela cultura do coco, pela pecuária e pelo extrativismo de mangaba para o de Indiaroba.

O Índice de Desenvolvimento Humano (IDH) de 0,588 para Belterra e de 0,580 para Indiaroba expressa vulnerabilidade socioeconômica (PNUD, [2020]). $\mathrm{Na}$ época da pesquisa, os dois municípios compuseram o território de atuação do Plano Brasil sem Miséria. A pesquisa foi realizada no período de 2011 a 2016 quando as catadoras não estavam mais participando do PAA e as agriculturas estavam no auge da participação.

Na seleção dos estudos de caso, consideramos semelhanças e diferenças entre os dois grupos de mulheres. Dentre as primeiras, a importante presença de mulheres na atividade agrícola e de coleta (nem sempre visibilizadas na literatura e nas estatísticas) e a participação no PAA. Quanto às diferenças, enfatizamos as trajetórias de comercialização dos produtos e a dificuldade de acesso aos recursos. As nossas principais interlocutoras foram as mulheres extrativistas e agricultoras afiliadas ao PAA, cujos perfis individuais foram caracterizados ${ }^{4}$, além de técnicos e gestores locais.

\footnotetext{
4 No Pontal, 70\% delas têm entre 30 e 50 anos, enquanto, no Trevo de Belterra, $40 \%$ estão nessa faixa e $40 \%$ entre 19 e 30 anos. Em se tratando da escolaridade, no Pontal, 24\% reconhecem-se como analfabetas, e $75 \%$ cursaram o ensino fundamental; as demais têm o ensino médio, e 1\% têm nível superior incompleto. No Trevo de Belterra, $38 \%$ das mulheres têm o ensino fundamental incompleto, $19 \%$ têm o fundamental completo, $9 \%$ têm o ensino médio incompleto, enquanto $25 \%$ têm o ensino médio completo e $9 \%$ têm o ensino superior incompleto. Nos dois lugares, elas são predominantemente casadas e com filhos, no Pontal $85 \%$ delas têm de 4 a 6 filhos. Esses números são bem menores no Trevo de Belterra, onde as agricultoras têm em média 3 filhos.
} 
Mapa 1 - Municípios de Belterra (PA) e Indiaroba (SE) com as respectivas localidades da pesquisa: Trevo de Belterra e Pontal

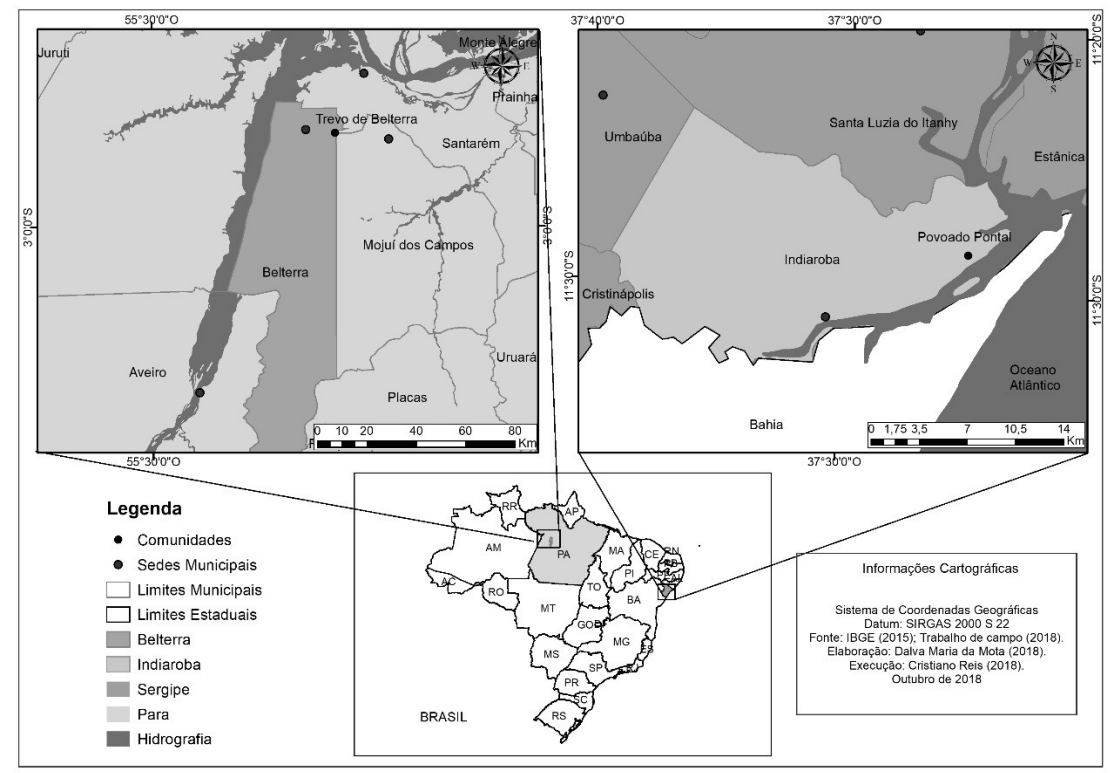

A nossa expectativa é que este artigo contribua para elucidar a importância do PAA (virtudes e críticas) para a reprodução social de dois grupos de mulheres que lideram o trabalho produtivo, mas que têm relação diferenciada com os recursos, num momento histórico em que, apesar das virtudes do programa em aliar objetivos econômicos e sociais, os seus recursos foram significativamente cortados e o PAA está praticamente extinto em 2018, em virtude da falta de prioridade governamental para a agricultura familiar.

\section{AS CATADORAS DE MANGABA NO PAA EM SERGIPE}

A participação das catadoras de mangaba no PAA ocorreu no período de 2007 a 2011. Segundo informações orais das entrevistadas, uma liderança e um político $^{5}$ divulgaram o PAA no Pontal, no ano de 2006, em razão da demanda de um pequeno grupo de catadoras de mangaba. Na sequência, eles elaboraram uma proposta para a Companhia Nacional de Abastecimento (Conab), visando incluir a mangaba no elenco dos produtos a serem comercializados no PAA.

\footnotetext{
Um vereador, membro da Cooperativa de Produção, Comercialização e Prestação de Serviços dos Agricultores Familiares de Indiaroba e Região (Cooperafir) - que na ocasião participava do PAA com agricultores familiares com 10 produtos diferentes - e o presidente da Associação dos Moradores do Povoado Pontal e Periferia.
} 
Para a viabilização da proposta, um arranjo institucional envolveu a Cooperativa de Produção, Comercialização e Prestação de Serviços dos Agricultores Familiares de Indiaroba e Região (Cooperafir), instituição que possibilitou a participação das catadoras de mangaba no PAA e é afiliada à Associação de Cooperação Agrícola dos Assentados da Região Sul (Ascosul). As doações foram recebidas pela Associação dos Moradores do Povoado Pontal e Periferia, beneficiada na modalidade CDS. Neste processo, as catadoras fundaram a Associação das Catadoras de Mangaba de Indiaroba (Ascamai), em Pontal.

Após a aprovação da proposta, apenas seis catadoras cadastraram-se no PAA, em 2007. As demais temiam ter acesso a dois programas de políticas públicas (mesmo que não haja impedimento legal), uma vez que, na condição de marisqueiras, elas eram beneficiárias do Seguro-Desemprego do Pescador Artesanal (SDPA). Ademais, tinham receio de que os recursos atrasassem e assim, comprometessem as necessidades dos membros do grupo doméstico. Além de temerem romper acordos de comercialização com os "atravessadores".

Na primeira "entrega" de mangaba para o PAA, houve dificuldades para disponibilizar, ao mesmo tempo, certo volume de frutos. Outra dificuldade foi encontrar uma instituição para doar o produto - a mangaba -, que finalmente foi enviado para o hospital de um município vizinho. Posteriormente, as doações foram para associações de moradores de comunidades vizinhas. O sucesso da primeira entrega estimulou outras catadoras que, sucessivamente, foram aderindo ao grupo, conforme dados do Quadro 1.

Quadro 1 - Catadoras no Programa de Aquisição de Alimentos (PAA) e frutos entregues de 2007 a 2011 no povoado Pontal (SE)

\begin{tabular}{|c|c|c|c|}
\hline Ano & $\begin{array}{c}\text { Número de catadoras } \\
\text { cadastradas no PAA }\end{array}$ & $\begin{array}{c}\text { Total de frutos } \\
\text { entregues (kg) }\end{array}$ & $\begin{array}{c}\text { Valor estimado de } \\
\text { recursos (R\$) }\end{array}$ \\
\hline 2007 & 6 & 8.000 & 8.000 \\
\hline $2008^{6}$ & 6 & 9.000 & 9.000 \\
\hline 2009 & 20 & 10.000 & 15.000 \\
\hline 2010 & 20 & 27.300 & 40.950 \\
\hline 2011 & 30 & 50.000 & 75.000 \\
\hline
\end{tabular}

Fonte: Pesquisa de campo.

Em 2007 e em 2008, o preço da mangaba praticado no PAA foi $\mathrm{R} \$ 1,00 / \mathrm{kg}$. A partir de 2009, chegou a $R \$ 1,50 / \mathrm{kg}$. A mudança do valor foi influenciada pela argumentação das catadoras dirigida ao dirigente da Conab por ocasião da reunião dos extrativistas em Brasília, em 2009. Nesta ocasião, "atravessadores" estavam pagando R \$ 0,90.

7 Estimativa com base na tendência observada e nas informações orais das catadoras entrevistadas. Os demais anos foram calculados a partir do controle do articulador local das "entregas" individuais. 
No primeiro ano de participação no PAA, em 2007, cada catadora nominalmente cadastrada "entregou” 1333kg. Em 2011, esse número alcançou $1666 \mathrm{~kg}$ por catadora, porque uma maior quantidade de catadoras destinava os frutos do seu trabalho e de sua família ao PAA, abrigadas no nome de parentas e vizinhas, conforme práticas de solidariedade tradicionalmente realizadas (MOTA et al., 2014). Esta estratégia foi fundamental para lidar com um empecilho burocrático para a participação de todas as catadoras no PAA - a falta da Declaração de Aptidão ao Pronaf (DAP) ${ }^{8}$. Assim, cada catadora cadastrada aceitou frutos de outra catadora no seu nome para que todas pudessem ganhar. Isso pode parecer "incorreto", "irregular", mas, na realidade, é a evidência de um tecido social forte, de uma capacidade coletiva de resistir, é a demonstração do desejo e da necessidade de permanecer na atividade. Por isso, essas práticas são vistas pelas catadoras, pelas lideranças e pelos pesquisadores como normais porque sabedores da condição de insegurança social que atinge as catadoras. Sabe-se, também, que não há discordâncias entre elas sobre esse tema e que se tratavam exclusivamente de acordos entre catadoras.

Tanto as "entregas" de frutos, como o recebimento oriundo da doação simultânea, constituíram-se em eventos sociais importantes no Pontal. Aproximadamente 80 pessoas participavam dos processos de "entrega" e de recepção, com destaque para a participação das crianças que, curiosas, estavam em todo o processo. Sob a liderança do presidente da associação de moradores e de catadoras de mangaba, estruturas de recepção de frutos (oriundos de outras comunidades para os habitantes do Pontal) e de "entrega" (oriundos do Pontal para serem entregues em outras comunidades) foram montadas em dias diferentes. Para a recepção de frutos, a sede da associação de moradores foi utilizada. No caso da venda da mangaba, duas estruturas foram montadas para atender as catadoras que moram em diferentes lugares do Pontal (uma casa em construção emprestada pelo proprietário e a sede da associação). Em ambas, balanças e caderno de anotação eram utilizados para controlar o volume de cada catadora. A "entrega" e o acondicionamento no caminhão eram feitos predominantemente pelas catadoras. Aproximadamente 40 mulheres participavam das atividades com a ajuda de algum dos seus cônjuges e filhos. A visibilidade delas, em ação como partícipes de uma política pública, constituiu motivo de orgulho e reconhecimento localmente.

O Programa Nacional de Fortalecimento da Agricultura Familiar (Pronaf) foi institucionalizado em 1996. A Declaração de Aptidão ao Pronaf (DAP) é uma condição para poder participar em programas de apoio à agricultura familiar, como o PAA. 
No ano de 2011, foi realizada a última "entrega". Os argumentos para a interrupção não são claros. Para uns, foram associados à rejeição dos funcionários das instituições receptoras em decorrência do volume de trabalho acarretado para processar o fruto da mangaba que, além de perecível, tem um leite viscoso que adere fortemente nas paredes dos recipientes. Para outros, foi decorrente da finalização do contrato da cooperativa com a Conab e da falta de agilidade para a apresentação de uma nova proposta.

\subsection{BOAS LEMBRANÇAS DO PAA NO PONTAL EM SERGIPE}

Como anteriormente analisamos (MOTA et al., 2014), os reflexos econômicos e políticos do PAA no povoado Pontal foram identificados na fala de todas as entrevistadas, associados à construção e reforma de casas, à compra de eletrodomésticos e de equipamentos para o trabalho no manguezal (canoa). Para além dos bens materiais, elas expressaram a satisfação pelo reconhecimento do valor do produto por elas coletado, anteriormente muitas vezes descartado por falta de mercado ou diante de uma oferta considerada humilhante em termos de preço. Mas, a maior satisfação relaciona-se ao fato de terem a DAP nos próprios nomes, uma ruptura com a prática vigente, que era atribuir ao homem a responsabilidade pela produção. Entretanto, nem todas as mulheres conseguiram a DAP em curto espaço de tempo, seja pela impossibilidade de reunir os documentos, seja pela dificuldade de deslocamento para a sede municipal, ou ainda pela insistência de alguns técnicos em privilegiar o homem como titular da DAP.

Em se tratando do pagamento, as catadoras de mangaba recebiam do PAA o valor em dinheiro conforme o peso das frutas em montantes que alcançaram até $\mathrm{R} \$ 2.000,00$. Os valores recebidos permitiam compras de maior valor, inclusive de equipamentos para potencializar o trabalho (fogão a gás e "freezer" para fazer e armazenar alimentos a serem vendidos nas praias, além de canoas para permitir o acesso a manguezais mais distantes). Mesmo as que recebiam menores quantias podiam fazer compras de maior porte quando somadas ao dinheiro que recebiam de outros programas sociais, como o seguro-desemprego. Nas palavras de uma catadora que adquiriu um terreno:

Foi suado. Porque assim, nós palavrou. Nós já tinha palavrado há muito tempo, né? E aí não dava certo. Sempre tinha um obstáculo. Aí foi que eu estava com o seguro para receber. Aí quando saiu os dois de uma vez. Aí eu peguei e aproveitei o defeso com o das mangabas do PAA (I. S. T., 46 anos, catadora de mangaba). 
Dentre as lembranças mais significativas, registra-se a possibilidade que os recursos advindos do PAA ofereciam às catadoras de permanecerem junto de suas famílias para a realização do trabalho. Em contraste, antes do PAA, elas viviam entre idas e vindas para trabalhar precariamente em bares e restaurantes de praias vizinhas, inclusive da Bahia.

Mesmo com tão boas recordações associadas ao PAA, todas as catadoras entrevistadas reconhecem que o acesso ao programa provocou algumas rivalidades localmente, principalmente com os proprietários e os gerentes (caseiros) de estabelecimentos que têm mangabeiras, nas quais elas tradicionalmente coletavam mediante acordos não monetários. Os proprietários e gerentes alegam que a venda das mangabas deveria beneficiar quem detinha a propriedade das terras, nas quais estavam as plantas com os frutos. $\mathrm{O}$ interesse do grupo de proprietários crescia à medida que a mangaba adquiria maior valor de troca sob influência do PAA.

A rivalidade desaguou em tensões que foram reveladas por uma intensificação do cercamento das propriedades com arame farpado e de interdição de coleta nos moldes tradicionais, como afirma uma entrevistada: "Ave Maria! Não era nem pra chegar perto! Aí pra baixo tem dono aí, melhor é não chegar nem perto [...] Vinha atrás da gente que nem um carcará pra tomar balde, gancho. E toma, até hoje toma [...]" (M. C., 25 anos, catadora de mangaba).

No elenco de conflitos entre defensores de diferentes concepções dos direitos relacionados ao usufruto de um recurso nativo, por um lado, o PAA influiu no acirramento da rivalidade entre proprietários de terra e mulheres extrativistas sem terra, as catadoras de mangaba. Por outro lado, possibilitou a resistência ao impedimento do acesso ao recurso com base no argumento de que participar de um mercado institucional proporcionado pelo Estado era sinônimo de reconhecimento social e de justiça quanto ao recebimento de pagamento pelos frutos do próprio trabalho.

Indagadas sobre a importância do PAA, as catadoras de mangaba unanimemente reconhecem que o projeto foi bom e deveria continuar, pois "Era um dinheirinho certo que a gente tinha". Para além do "dinheirinho", reconhecimento social e protagonismo numa política em seus próprios nomes.

\subsection{DIFICULDADES SEM O PAA: "TUDO VOLTA A SER UMA AVENTURA"}

No decorrer da atuação das catadoras de mangaba no PAA, registramos uma intensificação da dedicação ao extrativismo. Com a ruptura, em 2011, a pluriatividade volta a pontuar o cotidiano de cada uma das mulheres. Além de 
assumirem a responsabilidade pelas crianças, os idosos e pelas tarefas domiciliares (limpeza, comida e roupas), elas também trabalham como caseiras, faxineiras, domésticas, marisqueiras etc.

Em relação ao extrativismo, após o PAA, houve o aumento de pessoas que coletam mangaba, proporcionalmente à diminuição dos frutos. Segundo uma entrevistada, "tem mais catadora do que mangabeiras". A procura pela mangaba coincide com a privatização das áreas e a proibição do acesso.

Há unanimidade entre as entrevistadas que o PAA foi o primeiro programa de política pública que permitiu a comercialização da mangaba com segurança e estabilidade quanto ao pagamento. Com o fim do programa, tudo volta a ser uma "aventura", como explicitado no depoimento:

Era um dinheiro certo. [...]. Hoje, pra mim, não sei para as outras catadoras, eu só acho ruim por causa disso que a gente não tem esse dinheiro certinho que a gente tinha porque, por exemplo, no dia de entregar: olhe, tal dia pra entregar pra Conab. Aí a gente se esforçava. Vou me esforçar pra pegar uma quantidade boa, que para o outro mês a gente ter um dinheirinho bom também lá. E hoje, a gente não tem mais isso. Se for tirar pra. [..] ah, eu vou tirar pra ir pra feira. A feira é uma aventura, né? A gente vai pra feira e às vezes a feira dá boa, às vezes não dá (J. S., 45 anos, catadora de mangaba).

Além do retorno da incerteza quanto aos lugares de venda dos frutos, os preços oscilam, e as catadoras afirmam, em alguns casos, não ter garantia de pagamento. Consumidores nas feiras e atravessadores constituem os principais compradores. Também faz parte do campo das incertezas a quantidade de frutos a serem vendidos ao atravessador, que não possui a mesma disposição do PAA para adquirir a mangaba em grandes quantidades, como explicitado no depoimento:

Aí, no ano passado, eu cheguei até a chorar, nem imaginava [...]. A gente tirou muita mangaba, era na época de inverno, e quando a moça chegou, ela disse que não queria aquela quantidade. Eram 8 caixas e ela só queria 3 [...]. Aí, a gente foi chorar, né, a gente vai fazer o que com essas 5 caixas de mangaba se a gente não tem pra quem entregar? E na época da Conab não, a gente tinha certeza que quantos quilos tirasse, as caixas que a gente tirasse, a gente poderia entregar. Aí, agora a gente não tem a quem entregar, agora só tem prejuízo (R. T. S., 35 anos, catadora de mangaba).

Além das cercas, a inconstância dos preços e a dificuldade de comercialização têm forçado as catadoras de mangaba a intensificar a atividade de coleta de mariscos no manguezal, as iniciativas ligadas ao comércio e à prestação de serviços. 
O sentimento de "aventura" extrapola a questão do PAA e incide nos outros programas. A mesma entrevistada do depoimento acima destacou o sentimento de insegurança quanto ao seguro-desemprego da pesca artesanal, recordando os atrasos frequentes e contrapondo ao PAA. Para ela, nessas políticas elas não podem cobrar o dinheiro atrasado, porque ele não é fruto do trabalho delas. Ou seja, além de insegurança, o fim do projeto influencia na autoestima das mulheres: "Eu tinha, porque eu sabia [...] é meu. Eu entreguei. Eu tinha certeza que eu ia receber, porque eu tive o que entregar, né?” (R. T. S., 35 anos, catadora de mangaba).

A frustração pelo fato de não estar mais participando do PAA era compartilhada por todas as entrevistadas que também apontaram que a retirada dos recursos oriundos do PAA arrefeceu o dinamismo dos pequenos negócios e, consequentemente, a economia local.

\section{AGRICULTORAS DO TREVO DE BELTERRA NO PAA}

As agricultoras do Trevo Belterra participam do PAA desde 2009. A implantação do programa em Santarém, distante cerca de $40 \mathrm{~km}$ do Trevo e onde elas são cadastradas, decorreu de uma original articulação ${ }^{9}$ entre os atores sociais locais e as instituições governamentais que atuam naquele território municipal. Por parte dos atores, destaca-se a decisiva participação do Sindicato dos Trabalhadores e Trabalhadoras Rurais de Santarém (STTR) que fez um grande esforço para divulgar o programa na região. Ainda que todas as instituições governamentais exerçam funções complementares, cabe enfatizar as ações empreendidas pela Prefeitura Municipal de Santarém no período de 2004 a 2012, quando priorizou a agricultura familiar e, para isso, acionou várias instituições.

A operacionalização do PAA Municipal de Santarém é de competência da Coordenação Local do PAA, cuja rotina semanal inclui três eventos simultâneos de recepção dos produtos fornecidos pelos agricultores familiares e de doação dos alimentos às entidades beneficiadas. Por sua vez, também realizam o controle da entrega dos alimentos nas entidades beneficiadas. Em atendimento a esse cronograma, observamos que as agricultoras, na véspera da entrega, preparavam os produtos (higienização e armazenagem) e se deslocavam no dia da entrega até a sede da Associação dos Produtores Rurais de Santarém (Aprusan). Os maiores cuidados eram reservados às hortaliças, que precisavam ser regadas mesmo durante o transporte até Santarém.

O município de Santarém envolveu mulheres agricultoras de municípios vizinhos. 
Algumas agricultoras transportavam os produtos em ônibus. Outras se articulavam para fretar um caminhão. Ao chegar à sede da Aprusan, quando não estavam na companhia de outros membros da família, pagavam para alguém descarregar e pesar, sob a supervisão dos técnicos do PAA.

Enquanto as agricultoras faziam a entrega dos produtos, as entidades socioassistenciais que seriam contempladas com os alimentos aguardavam. Apesar de estarem no mesmo espaço, não observamos a existência de uma relação entre elas. Na verdade, mesmo que as agricultoras soubessem da destinação dos produtos que vendiam para o PAA, nem sempre os beneficiados vinculados às entidades socioassistenciais tinham noção de sua proveniência.

Dados sobre o ano de cadastramento, o número de mulheres e o valor recebido por ano pelas agricultoras do Trevo de Belterra no PAA estão no Quadro 2.

Quadro 2 - Número de cadastros e valor estimado da entrega dos produtos ao PAA no Trevo de Belterra, de 2009 a 2013

\begin{tabular}{|c|c|c|}
\hline Ano & $\begin{array}{c}\text { Número de agricultoras } \\
\text { cadastradas no PAA }\end{array}$ & $\begin{array}{c}\text { Valor estimado de recursos } \\
\text { recebidos (R\$) }\end{array}$ \\
\hline $2009^{10}$ & 2 & 9.000 \\
\hline 2010 & 10 & 45.000 \\
\hline 2011 & 12 & 54.000 \\
\hline 2012 & 15 & 67.500 \\
\hline 2013 & 21 & 94.500 \\
\hline
\end{tabular}

Fonte: Coordenação Local do PAA Santarém. Elaborado pelos autores com base em Guimarães (2014).

Em 2009, apenas duas mulheres agricultoras do Trevo de Belterra cadastraram-se no PAA e realizaram a entrega dos produtos agrícolas, na modalidade CDS. Elas explicaram que souberam do PAA por intermédio da Aprusan, à qual são filiadas, e foram informar-se no STTR de Santarém, no STTR de Belterra e também na Empresa de Assistência Técnica e Extensão Rural (Emater) para saber como poderiam participar do PAA. Como visto, a iniciativa de participar do PAA partiu delas, pois viam no programa uma possibilidade de comercializar seus produtos agrícolas e de aumentar a renda familiar. Na sequência, em 2010, houve um esforço dos técnicos que executavam o PAA localmente para alcançar o número de agricultores familiares necessário para implantar o programa na nova modalidade indicada pelo MDS. Em 2011, quando não houve essa ação

$\overline{10}$ Modalidade $C o m p r a$ Direta Local da Agricultura Familiar. 
dos técnicos, apenas outras duas mulheres cadastraram-se no PAA. Portanto, mesclaram-se iniciativas individuais e institucionais para a consolidação do PAA localmente porque havia dúvidas em relação ao seu funcionamento. A falta de esclarecimentos por parte do STTR de Belterra foi um dos principais entraves a que elas buscassem participar do programa mais intensamente.

Grisa et al. (2009) também constataram a falta de divulgação pelos executores do PAA e o desconhecimento dos objetivos e da forma de funcionamento do programa por parte dos agricultores como alguns dos limites do PAA, principalmente onde existe pouca participação dos agricultores familiares em organizações coletivas, como associações e cooperativas.

O maior número de mulheres agricultoras no PAA, principalmente na modalidade CDS executada pelo PAA Municipal de Santarém, deve-se ao fato de essa modalidade priorizar a compra dos produtos agrícolas que, geralmente, são cultivados pelas mulheres agricultoras:

As modalidades do PAA de Compra Direta com Doação Simultânea [...] vêm propiciando a criação de um mercado "institucional", com preços justos, para os produtos tradicionalmente vinculados à esfera feminina, ao "autoconsumo", à "subsistência" e ao "quintal", cultivados em áreas próximas à casa, ou em áreas não aproveitadas para cultivos comerciais (SILIPRANDI; CINTRÃO, 2011, p. 21).

Embora o MDS (2014) tenha estipulado o percentual de $40 \%$ para a participação de mulheres no PAA e o PAA Municipal de Santarém em 2013 tenha cumprido essa exigência, especulamos que a força de trabalho feminino na produção direcionada ao programa é superior.

O cadastro e a entrega de produtos pelas mulheres não são suficientes para avaliar sua participação no PAA ou, mesmo, para ponderar o incentivo às transformações nas relações de gênero no meio rural brasileiro. Mesmo que reconheçam que essa política pública valoriza o trabalho das mulheres, Siliprandi e Cintrão (2011, p. 28) afirmam que "[...] ainda existem fortes desafios para que [o PAA] possa contribuir de maneira efetiva para a construção de uma maior autonomia econômica das mulheres", como também para o reconhecimento de que, tanto na esfera doméstica, quanto na esfera produtiva, as mulheres trabalham para garantir a reprodução social, diferentemente da compreensão que as relaciona à "ajuda". 


\subsection{TRABALHO AGRÍCOLA DAS MULHERES VISANDO ATENDER O PAA}

Diferentemente das extrativistas, as mulheres agricultoras que participam do PAA têm acesso à terra no Trevo de Belterra, da seguinte forma: em $62 \%$ dos casos, as terras são próprias; em 24\%, são arrendadas; em 14\%, são "mistas" (próprias e arrendadas). Nas áreas arrendadas, predominam mulheres jovens que também pagam trabalhadores ocasionalmente. $\mathrm{O}$ tamanho das áreas varia de 1 a 3 ha para $57 \%$ das entrevistadas, de 4 a 7 ha para 19\%, ficando as demais com áreas entre 7 e 32 ha. No caso específico das agricultoras afiliadas ao PAA, elas utilizam uma parte da terra da família e outra parte na condição de arrendamento. As áreas sob seu domínio alcançam até 0,5 ha; não há cercas ou algo semelhante, são os tipos de cultivos que delimitam as áreas arrendadas e as áreas da família.

As mulheres agricultoras investem especialmente na produção de hortaliças e frutas, mais facilmente compradas pelo PAA. Elas cultivam cerca de 30 produtos segundo arranjos variáveis, entre os quais melancia, abacaxi, mamão, banana, jerimum, repolho, maxixe, beterraba, tomate, pimentão verde, alface, coentro, cebolinha e couve. Além disso, praticam o extrativismo de pupunha e de mel e produzem farinha de mandioca oriunda da roça da família, além de criarem galinhas ${ }^{11}$.

Siliprandi e Cintrão (2011) explicam que o investimento na produção de hortaliças e frutas é estimulado pelo PAA. Não é diferente no Trevo Belterra, onde, na divisão social do trabalho, esses produtos são geralmente cultivados pelas mulheres agricultoras nos quintais e destinados ao autoconsumo, em razão do "[...] pouco ou nenhum acesso ao mercado, tendo o excedente trocado ou oferecido a vizinhos e parentes, ou simplesmente "perdido"' (SILIPRANDI; CINTRÃO, 2011, p. 20). Diferentemente, o PAA influi diretamente na seleção dos produtos agrícolas e na organização do trabalho coordenado pelas mulheres agricultoras, que veem produtos, antes destinados exclusivamente ao consumo, serem valorizados.

É importante observar que todas as mulheres agricultoras afiliadas ao PAA no Trevo de Belterra investiram na diversificação dos cultivos agrícolas e aumentaram seu nível tecnológico com os recursos do programa, que paga preços justos, o que incentiva também a maior produção. Assim, cultivos que antes eram feitos nos arredores da casa, como as hortaliças e as frutas, passaram a ocupar um

\footnotetext{
${ }_{11}$ Roça é uma área preparada para o cultivo de culturas anuais por meio da derrubada da vegetação original, da queimada do material orgânico e do plantio sem preparo do solo. Antes da participação no PAA, as mulheres produziam, juntamente com os demais membros da família, feijão, arroz, milho, soja, mandioca, macaxeira, jerimum, banana e pimenta-do-reino.
} 
lugar na unidade produtiva, junto com as culturas mais tradicionais - que eram menos cultivadas no momento da pesquisa, como é o caso da mandioca.

Em se tratando do uso dos recursos na produção, todas elas afirmaram que um percentual do dinheiro recebido da venda ao PAA é investido na compra de sementes, pesticidas, adubo mineral, ferramentas, pagamento de diarista, aluguel de pequenas máquinas e do borrifador, construção de caixa d'água para irrigação etc. Os investimentos facilitam o trabalho produtivo, diminuem a penosidade e aumentam o volume da produção.

Quanto à divisão do trabalho, as mulheres agricultoras desenvolvem todas as atividades para o cultivo de hortaliças, que vão do preparo do solo à colheita. $\mathrm{Na}$ ausência dos homens, elas realizam, inclusive, a aplicação de pesticidas. Essa última tarefa é considerada por elas um trabalho árduo e pouco apreciado, pois o equipamento pesa aproximadamente $20 \mathrm{~kg}$ e o produto químico provoca alergia e enjoo. Elas ponderam que os homens estão mais habituados do que elas a esse tipo de tarefa.

A fala de uma das mulheres sobre as influências do PAA no volume e na intensidade do trabalho indica: "com o PAA, pelo contrário, trabalho menos e ganho mais" (C. S. R., 52 anos, agricultora familiar). Nesse caso, ela não está se referindo à jornada de trabalho, mas à intensidade do trabalho.

Com o acesso ao mercado institucional do PAA, as mulheres têm a garantia de venda a preços justos, o que reflete nas suas condições de autonomia econômica, aqui entendida no sentido de Fernandes (2011, p. 33): “[...] a autodeterminação para organizar e desenvolver o seu trabalho, definindo as próprias metas e agindo em consequência delas, a capacidade de gerar renda e de decidir a forma que essa renda será utilizada, seja para gastos próprios ou com a família”.

Como parte das estratégias de reprodução social, os cônjuges de algumas agricultoras migram durante o verão para trabalhar em outras atividades em decorrência da falta de água que influi no arrefecimento das atividades agrícolas. Quando retornam, eles “ajudam” as mulheres nos fins de semana e nas férias. Dificilmente as mulheres saem da localidade para trabalhar fora, com exceção de uma mulher que, além do trabalho na agricultura, vende perfumes por meio de catálogos e faz artesanato (crochê e redes). Durante o inverno, essa entrevistada trabalha na agricultura; no verão, ela migra para o garimpo para trabalhar como cozinheira para os "peões" e comercializa as redes fabricadas por ela mesma. Para as demais, não registramos migrações, porque elas têm entre as suas responsabilidades as crianças e os idosos. Em consequência, uma delas expressou ser mais justo o PAA no nome das mulheres, porque "o homem sempre tem outra coisa", logo, usufrui de maior mobilidade mediante a condição de gênero. 
$\mathrm{Na}$ ausência dos homens, as mulheres coordenam todas as atividades agrícolas. Mas existem diferentes arranjos, porque duas delas afirmaram que só assumem o comando dessas atividades se eles não estão, e, quando eles retornam, esses domínios voltam a ser deles. Entretanto, por meio de observações, constatamos que algumas delas tanto lideram a comercialização da produção, quanto cuidam dos trâmites burocráticos para o recebimento do PAA e, ainda, resolvem os assuntos do seguro-desemprego recebido pelo marido. Elas também deixaram escapar que fazem a comercialização, "porque ele não [...] ele não é assim [...] ele é meio tímido [...] Ele não é como essas pessoas [...] que tem pessoas que são muito envolvidas nessas coisas, né?" O contraste entre o discurso e as evidências parece explicitar o reforço dos lugares tradicionais de homens e mulheres nas esferas da reprodução e da produção, respectivamente, mas num contexto em que elas são estimuladas a romper com essa oposição.

As observações sinalizaram que são elas que lideram as atividades no lote, embora, ocasionalmente, os cônjuges participem. Porém, as principais atividades deles, em determinados períodos do ano, são a pesca, o garimpo e o trabalho assalariado. Por isso, eles não participam de todas as etapas do trabalho agrícola e da comercialização para o PAA.

As ações propostas pelo PAA reforçaram as demandas das mulheres agricultoras no Trevo Belterra, pois a maioria delas menciona que há muitos anos desejavam planejar e organizar a produção em médio e em longo prazo. Tal demanda não coincidia com a dos homens que não davam a devida importância a essa questão até o momento em que elas ingressaram no PAA e auferiram rendimentos. As palestras, os minicursos e as oficinas realizadas em parceria com a Emater, o Serviço de Apoio às Micro e Pequenas Empresas (Sebrae), os STTR de Santarém e de Belterra, mais a Aprusan contribuíram para que elas tivessem mais segurança quanto às mudanças produtivas e institucionais (afiliação a associações e cooperativas). Além disso, adquiriram um aprendizado social por venderem juntas e terem participado dos debates no decorrer da implantação do programa para reforçar as ideias sobre a produção e a comercialização. Dessa forma, o PAA, ao estimular a participação direta das mulheres, formalmente nominadas na DAP, aumenta a credibilidade do trabalho realizado por elas para além do espaço reprodutivo.

O conjunto das agricultoras entrevistadas critica a concentração das vendas, agendadas pela Coordenação Local do PAA, nos últimos meses do ano - outubro, novembro e dezembro - e reivindica a sua distribuição ao longo do ano para melhor atender as suas necessidades. Uma agricultura afirmou: "a única coisa que eu queria era que o PAA melhorasse, era que pegasse 
[os produtos] no tempo certo". O tempo certo mencionado refere-se ao período do inverno, quando elas produzem mais e os custos são menores, mesmo para aquelas que possuem um sistema de irrigação. No verão, precisam de mais água, e os custos aumentam por conta do consumo de energia elétrica para a bomba. Outro aspecto, não verbalizado, mas perceptível, é a falta de informação sobre o funcionamento do programa. As agricultoras atribuem a essa carência o fato de não compreenderem a concentração das vendas e creem que, se tivessem mais informações, atuariam mais ativamente para serem ouvidas.

Mesmo com as críticas, as mulheres do Trevo de Belterra avaliaram positivamente a experiência com o PAA. Mas, nem por isso, conseguiram permanecer no programa um ano depois da nossa pesquisa. Em decorrência do arrefecimento do programa, elas não foram recadastradas em 2017, interrompendo assim as suas participações no PAA. Em consequência, não comercializaram a produção preparada para tal fim (SANTOS; SILVA; QUARESMA, 2018).

\subsection{INTENSIFICAÇÃO DO CONSUMO E AQUISIÇÕES COM RECURSOS DO PAA}

Os recursos advindos do PAA influem no consumo e, consequentemente, nas compras das famílias, como reconhecem todas as agricultoras entrevistadas. Elas informaram que, imediatamente após o recebimento do recurso, são feitas compras de alimentos para serem consumidos no prazo de um mês ou mais. Normalmente, produtos não perecíveis que, comprados em grosso, são mais baratos. No dia a dia, se faltar algo para o consumo, alguém da familia recorre aos "mercadinhos" locais para adquiri-lo. No geral, não constatamos diversificação nos itens comprados, mas houve mudança em relação às quantidades. Se não há mudança no que compram, há no que consomem, pois é frequente a alusão a hortaliças diariamente na mesa da família.

Apesar da reconhecida maior capacidade de compra com os recursos do PAA, as mudanças mais significativas deram-se na esfera da produção e de infraestrutura (poço, sistema de irrigação, galpão para a embalagem dos produtos e caixa d'água). Para 100\% das entrevistadas, é nesses quesitos que se concentram as maiores aquisições incentivadas pelos preços que consideram justos para o que produzem.

Apenas ocasionalmente, ouvimos referências à aquisição de móveis e a reformas de casa. Entretanto, outros anseios movem as mulheres a utilizar o recurso do PAA: um deles é a busca de ingresso no ensino superior para exercer outras profissões. Esse é o caso de mulheres mais jovens que participam 
do projeto ou têm seus sonhos financiados por uma mãe que se integrou ao programa e, com isso, pôde ajudar a filha a concretizar esse objetivo.

\section{PARA FINALIZAR: O PAA REFORÇA A REPRODUÇÃO SOCIAL?}

$\mathrm{O}$ artigo trata da experiência de dois grupos de mulheres (extrativistas e agricultoras) no PAA no Nordeste e no Norte do Brasil, sob o enfoque das estratégias de reprodução social, tema que tem sido historicamente tratado no âmbito dos estudos rurais. Nesse sentido, Almeida (1986) faz um balanço e aponta estudos que mostram o que ocorre no processo de reprodução social

[...] a unidade familiar se reproduz no ciclo anual, combinando trabalho, recursos naturais e conhecimento tradicional para atender ao consumo familiar e para repor os insumos necessários ao reinício do processo: trata-se do que se tem chamado de reprodução, mas de uma reprodução de ciclo curto, anual. Outros estudos tratam de como a unidade familiar (ou um conjunto delas) se reproduz no ciclo geracional, ou seja, como famílias se perpetuam. Trata-se de um ciclo longo de reprodução (ALMEIDA, 1986, p. 67).

Ainda, segundo o autor, "uma maneira de expressar tudo isso é dizer que famílias adotam estratégias micro (de curto e de longo prazo) como resposta a pressões macroeconômicas e políticas (preços, leis)" (ALMEIDA, 1986, p. 67), como observado nos dois grupos de mulheres aqui analisados a partir da afiliação ao PAA.

O tema da reprodução social também constou nas preocupações de Brumer e Anjos (2008), que, mediante revisão bibliográfica, afirmam:

Assim, pesquisas sobre reprodução da agricultura familiar no curto prazo envolvem questões relacionadas às formas e meios de produção (como a apropriação e uso de tecnologias) e sua organização, na qual se incluem a divisão de trabalho entre os membros da família e as relações sociais estabelecidas com outros agentes sociais e instituições (BRUMER; ANJOS, 2008, p. 8).

Não passa despercebido para as autoras que os diferentes estudos também sinalizam as condições de permanência - ou reprodução - da unidade produtiva enquanto tal, envolvendo o trabalho dos membros da família e, segundo as nossas observações, o trabalho eventualmente contratado. Do mesmo modo como destacado por Almeida (1986), elas levam em conta as diferentes formas de utilização da terra, de alocação do trabalho, do uso de recursos naturais e como eles podem garantir ou não a existência da unidade produtiva em curto prazo e por mais de uma geração. 
Mediante as contribuições dos dois estudos, concluímos que as mulheres agricultoras e extrativistas, no intuito de reproduzir as suas condições de existência (no âmbito do grupo doméstico), foram apoiadas por um programa específico de política pública. Com o PAA, inaugurou-se um novo modelo de comercialização, que garante a compra dos produtos a preço justo de produtores familiares. Uma agricultora afirmou: "a gente já planta sabendo que vai vender, aí trabalha com mais vontade, né? [risos]” (M. G. T., 45 anos, agricultora familiar). O contraste é estabelecido com as inconveniências dos mercados convencionais ali existentes:

Se a gente achasse quem vendesse na porta era melhor [...] pra ti levantar de madrugada para esperar ônibus, no mercadão a coisa mais difícil é tu achar uma banca para tu vender teu produto. Além de tu não arrumar vaga no mercadão, tu tem que achar um marreteiro para tu vender, senão tu fica andando por lá. Tem vez que tu passa a semana sem conseguir vender. Aí preferível não ir, porque cada vez que tu vai, tu paga ônibus, né? E merenda e ainda paga a feira para tu usar (M. A. S., 45 anos, agricultora familiar).

Em se tratando das estratégias de reprodução social à luz dos estudos citados, há diferenciação entre as agricultoras (que têm acesso à terra) e as extrativistas (que não têm terra e que dependem da coleta em terras de terceiros). Como tal, os impactos do PAA nas condições objetivas e subjetivas de reprodução social têm especificidades. A consequência mais visível é a maior ou menor capacidade de planejar a produção e de manter uma frequência de participação no programa, uma vez que o PAA está desenhado para lidar com quem tem previsibilidade.

Nos processos de coleta e de produção, tanto extrativistas quanto agricultoras aliaram o trabalho familiar, os recursos naturais e o conhecimento tradicional, havendo evidência de dependência do mercado de insumos externos por parte das agricultoras. Os processos de trabalho sob a influência da afiliação ao PAA sofreram mudanças nos dois grupos. Para as catadoras de mangaba, houve a intensificação da coleta, o maior envolvimento dos membros da família e a busca de áreas mais distantes, dada a escassez local do fruto. Entretanto, não se observaram mudanças nas práticas de trabalho, mesmo que o trabalho tenha aumentado. Para as agricultoras, as mudanças incidiram na intensificação do uso da terra, na organização do trabalho e no nível tecnológico, com a adoção de práticas exógenas, mas o trabalho tornou-se mais leve.

Em ambos os casos, membros do grupo doméstico foram estimulados a participar mais ativamente dos processos de trabalho mediante o incentivo financeiro, a garantia de comercialização, os investimentos para melhorar a produção (no caso das agricultoras) e o reconhecimento social associado à obtenção de preço justo pelo trabalho. Estratégias micro de curto prazo 
no cotidiano dos dois grupos foram incentivadas no decorrer da afiliação ao PAA. Assim, com o suporte do PAA, a reprodução social, em curto prazo, foi reforçada nos dois grupos de mulheres. Mas a extinção do PAA no Pontal influiu na fragilização da visibilidade das extrativistas e na desarticulação das lideranças, dificultando a reprodução social em longo prazo. Para as agricultoras, a reprodução social foi fortalecida pela atração de membros da família para trabalhar junto com elas e pelo reforço das condições de produção. A redução da penosidade do trabalho, a garantia de mercado e a valorização social contribuem para que queiram persistir como agricultoras, tema a ser investigado quanto ao que ocorre com a inexistência do PAA, a partir de 2017.

Em se tratando da reprodução geracional, de longo prazo, os efeitos do PAA foram diversificados em função da condição de acesso aos recursos produtivos. Enquanto as agricultoras tiveram as suas condições de acesso à terra, de redução do caráter penoso do trabalho e de socialização dos jovens reforçadas, as extrativistas viram-se gradativamente excluídas do acesso aos recursos, o que tem implicações em sua própria condição de extrativista e, consequentemente, na socialização dos seus filhos. A reprodução geracional encontrava-se assim reforçada em um grupo e ameaçada em outro, que não tinha o acesso garantido aos recursos extrativistas.

Concordamos que as agricultoras e extrativistas sentiram-se valorizadas pelo trabalho e, consequentemente, para além da esfera dos cuidados e da casa. Para as extrativistas, no auge do PAA, houve a valorização da sua condição identitária, associada a uma ocupação. Já as agricultoras têm sido consideradas uma referência quanto à qualidade dos produtos e ao trabalho de mulheres na agricultura da região.

Para os dois grupos, o PAA é um programa considerado de grande relevância e diferenciado, porque valoriza os produtos locais, o trabalho da família e, particularmente, o trabalho das mulheres. Os preços justos pagos e o mercado garantido são ressaltados como uma novidade, em contraste com as cadeias de comercialização tradicionais, consideradas desvantajosas. As extrativistas, que perderam o acesso ao programa, ora submersas nessas últimas cadeias, lembram o PAA com "nostalgia", porque se veem vulneráveis por falta de compradores locais e por causa da oscilação dos preços. As agricultoras usufruíam da credibilidade que tem sido construída quanto à qualidade dos produtos, continuamente estimulada pelos técnicos da extensão.

Como conclusão geral, reforçamos os achados de outros analistas, entre os quais, Delgado (2013), que compreende o PAA como uma política que reúne objetivos econômicos e sociais, dinamiza processos produtivos, incentiva 
a organização das mulheres e contribui para um maior bem-estar (dieta, bens móveis e autoestima). Esse programa deixou de ser prioridade governamental desde 2016, e houve uma significativa redução dos recursos.

\section{REFERÊNCIAS}

ALMEIDA, M. W. B. Redescobrindo a família rural. Revista Brasileira de Ciências Sociais, São Paulo, v. 1, n. 1, p. 66-93, 1986.

BECKER, H. S. Métodos de pesquisa em ciências sociais. Tradução de Marco Estevão e Renato Aguiar. 3. ed. São Paulo: Hucitec, 1997. 178 p.

BRASIL. Lei $\mathbf{n}^{\mathbf{0}} \mathbf{1 0 . 6 9 6}$, de 2 de julho de 2003. Dispõe sobre a repactuação e o alongamento de dívidas oriundas de operações de crédito rural, e dá outras providências. Brasília, DF: Presidência da República, [2003]. Disponível em: http://www.planalto.gov.br/ccivil_03/LEIS/2003/L10.696. htm\#: :text=L10696\&text=LEI $\% 20$ No\%2010.696\%2C\%20DE $\% 202 \% 20$ DE $\% 20 J U L H O \% 20 D E \% 202003$.\&text $=$ Disp $\%$ C3\%B $\%$ e $\% 20$ sobre $\% 20$ a $\% 20$ repactua $\%$ C3\%A7\%C3\%A30\%20e,rural $\% 2 C \% 20$ e $\% 20 \mathrm{~d} \% \mathrm{C} 3 \%$ A $1 \% 20$ outras\%20provid\%C3\%AAncias. Acesso em: 21 fev. 2017.

BRUMER, A.; ANJOS, G. Gênero e reprodução social na agricultura familiar. Revista NERA, Presidente Prudente, v. 11, n. 12, p. 6-17, jan./jun. 2008.

CHMIELEWSKA, D.; SOUZA, D.; LOURETE, A. A. O Programa de Aquisição de Alimentos da Agricultura Familiar (PAA) e as práticas dos agricultores participantes orientadas ao mercado: estudo de caso no Estado de Sergipe. Brasília, DF: IPEA, 2010. (Texto para Discussão, n. 1510).

DELGADO, G. C. Pesquisa de avaliação de concepção e implementação do Programa Aquisição de Alimentos - PAA: relatório de avaliação do PAA (Síntese). Brasília, DF: Conab; PNUD, 2013. 17 p. Mimeografado.

DORETTTO, M.; MICHELLON, E. Avaliação dos impactos econômicos, sociais e culturais do Programa de Aquisição de Alimentos no Paraná. Sociedade e Desenvolvimento Rural, Brasília, DF, v. 1, n. 1, p. 107-138, 2007. Disponível em: http://www.iapar.br/arquivos/File/zip_pdf/aval_impact_ econo.pdf. Acesso em: 21 fev. 2017.

FERNANDES, T. Entre campo e casa: a autonomia da mulher e o extrativismo da mangaba. 2011. 138 f. Dissertação (Mestrado em Agriculturas Familiares e Desenvolvimento Sustentável) - Universidade Federal do Pará; Embrapa Amazônia Oriental, Belém, 2011. 
FORTES, M. O ciclo de desenvolvimento do grupo doméstico. Brasília, DF: UnB, 2011.

GARCÍA, B.; OLIVEIRA, O. La familia y el trabajo: principales enfoques teóricos e investigaciones sociodemográficas. In: GARZA TOLEDO, E. (coord.). Tratado latinoamericano de sociología. Barcelona: Anthropos Editorial; Cidade do México: Universidad Autónoma Metropolitana, 2006. p. 148-170.

GRISA, C.; SCHMITT, C. J.; MATTEI, L. F.; MALUF, R. S.; LEITE, S. P. O Programa de Aquisição de Alimentos (PAA) em perspectiva: apontamentos e questões para o debate. Rio de Janeiro: UFFRJ/CPDA, 2009. 24p. Disponível em: http://oppa.net.br/acervo/publicacoes/Pesquisa_AABR-OPPA_Texto_ PAA_versao_livro.pdf. Acesso em: $21 \mathrm{fev} .2017$.

GUimARÃES, J. F. Programa de Aquisição de Alimentos (PAA): influências sobre o trabalho das mulheres agricultoras do Trevo de Belterra, Estado do Pará. 2014. 140 f. Dissertação (Mestrado em Agriculturas Familiares e Desenvolvimento Sustentável) - Universidade Federal do Pará; Embrapa Amazônia Oriental, Belém, 2014.

HEREDIA, B. M. A.; CINTRÃO, R. P. Gênero e acesso a políticas públicas no meio rural brasileiro. Revista Nera, Presidente Prudente, ano 9, n. 8, p. 1-28, jan./jun. 2006.

IBGE. Cidades. IBGE, Rio de Janeiro, 2020. Disponível em: https://cidades. ibge.gov.br/brasil/. Acesso em: 20 maio 2020.

MDS. Programa de Aquisição de Alimentos: manual operativo, modalidade compra com doação simultânea, operação por meio de termo de adesão: 2014. Brasilia, DF: Ministério de Desenvolvimento Social e Combate à Fome, 2014. 175 p. MOTA, D. M.; SCHMITZ, H.; SILVA JÚNIOR, J. F.; PORRO, N. M.; OLIVEIRA, T. C. V. As catadoras de mangaba no Programa de Aquisição de Alimentos - PAA: um estudo de caso em Sergipe. Revista de Economia e Sociologia Rural, Piracicaba, SP, v. 52, n. 3, p. 241-262, jul./set. 2014.

PAULILO, M. I. S. A inadequação das políticas públicas no aumento da satisfação e do bem-estar das mulheres rurais. In: WORLD CONGRESS OF RURAL SOCIOLOGY, 13., 2012, Lisboa. Anais [...]. Lisboa: International Rural Sociology Association: Universidade Técnica de Lisboa: Instituto Superior de Ciências Sociais e Política, 2012. 
PNUD. Atlas do Desenvolvimento Humano no Brasil. Atlas Brasil, [S. l.], [2020]. Disponível em: http://www.atlasbrasil.org.br/2013/. Acesso em: 20 maio 2020 .

SANTOS, Á. O.; SILVA, D. W.; QUARESMA, E. Mulheres agricultoras e o PAA: participação no processo produtivo e comercialização. In: INTERNATIONAL CONFERENCE ON AGRICULTURE AND FOOD IN AN URBANIZED SOCIETY, 3., 2018, Porto Alegre. Anais [...]. Porto Alegre: UFRGS: AgUrb, 2018. p. 1-8.

SILIPRANDI, E.; CINTRÃO, R. As mulheres agricultoras no Programa de Aquisição de Alimentos (PAA). Segurança Alimentar e Nutricional, Campinas, v. 18, n. 2, p. 12-32, 2011.

VAleriano, C. A. N. O Programa de Aquisição de Alimentos como instrumento mediador para o desenvolvimento local: o caso da CRP doação através do MMNEPA em Santa Maria do Pará. 2012. 131 f. Dissertação (Mestrado em Gestão de Recursos Naturais e Desenvolvimento Local na Amazônia) - Programa de Pós-Graduação em Gestão dos Recursos Naturais e Desenvolvimento Local na Amazônia, Núcleo de Meio Ambiente, Universidade Federal do Pará, Belém, 2012.

ZIMMERMANN, S. A. Políticas públicas e arranjos institucionais: o Programa de Aquisição de Alimentos da Agricultura Familiar (PAA). In: CONGRESSO BRASILEIRO DE SISTEMAS DE PRODUÇÃO, 7., 2007, Fortaleza. Anais [...]. Fortaleza: Embrapa Agroindústria Tropical, 2007. Não paginado.

Texto submetido à Revista em 24.05.2019

Aceito para publicação em 15.05.2020 
